\title{
Formação pedagógica de professores da educação profissional e tecnológica numa instituição Brasileira
}

\author{
Teacher training for teachers of professional and technological education \\ in a Brazilian institution
}

\author{
Alfredo Bravo Marques Pinheiro*, Maria Deuceny da Silva Lopes Bravo Pinheiro**, Carlos Manuel Folgado \\ Barreira***, Maria da Piedade Vaz Rebelo**** \\ * Doutorando do Curso de Ciências da Educação, Faculdade de Psicologia e Ciência da Educação da Universidade de Coimbra, \\ Bolsista da Capes; **Doutorando do Curso de Ciências da Educação, Faculdade de Psicologia e Ciência da Educação da \\ Universidade de Coimbra, Bolsista da Capes/Programa Ciência sem Fronteiras; ***Faculdade de Psicologia e Ciência da Educação \\ da Universidade de Coimbra; ****Faculdade de Matemática da Universidade de Coimbra.
}

\begin{abstract}
Resumo
A presente comunicação faz uma abordagem sobre o que é ser professor na perspectiva da prática reflexiva, agregando características do saber teórico e pedagógico aos contornos individuais de quem ensina, trazendo contributos no processo ensino-aprendizagem. As preocupações com a formação pedagógica dos professores, especificamente daqueles que atuam na Educação Profissional e Tecnológica, revelam o distanciamento entre a formação pedagógica e formação específica. A formação de professores no âmbito desses cursos tem suscitado fóruns de discussão, tendo como preocupação desenvolver uma formação de qualidade que integre preparação didático-pedagógica orientada pelas necessidades dos professores tanto na formação inicial como na continuada.

Palavras-chave: Formação de Professores, formação continuada, educação profissional.
\end{abstract}

\begin{abstract}
This study presents a reflection on what to be a teacher is like. It is performed from the reflective perspective bringing together characteristics of theoretical and pedagogical knowledge of every individual who teaches, this way contributing with the teaching-learning process. The concerning about the pedagogical formation of teachers, mainly those who are working in Technical and Professional courses, show the distance between pedagogical and specific formation. The formation of teachers has given rise forums for discussion which concern the development of a high quality formation which can also integrate a didactical- pedagogical preparation guided by the needs of teachers, whether in initial or continual level of formation.

Key words: Teachers' formation, continual formation, professional education.
\end{abstract}

\section{A vivência e o conhecimento específico}

Quando recém saídos das universidades, os docentes recebem formação que nem sempre é suficiente para solucionar os problemas que surgem em sua vida docente, gerando uma crise de confiança (Alarcão, 1996), sendo esta a preocupação em relação à sua formação. A falta dessa confiança cria problemas para lidar com o dia-a-dia dos docentes, cuja importância à formação profissional dos estudantes é fundamental, sobremaneira no aprendizado técnico.

O modo como o professor ensina está intimamente ligado àquilo que ele é quando desenvolve o ensino (Nóvoa, 2000), diferente do século passado, quando os professores eram entendidos como técnicos que apenas cumpriam ordens elaboradas, normalmente, por profissionais (pedagogos) que invariavelmente encontravam-se fora das salas de aula (Damião, 2011).

A falta de preparo didático-pedagógico que a maioria dos educadores da formação técnica e tecnológica tem ao sair de sua graduação impõe certas restrições que só serão percebidas ao longo da trajetória em sala de aula. A necessidade de uma formação continuada que anule aquela desconfiança inicial torna-se requisito almejado pelos profissionais educadores.

Os programas de formação continuada, elaborados e disponibilizados pelas diversas instituições e, muitas vezes, ciceroneadas por legislações governamentais, que deveriam completar a falta de preparo pedagógicodidático e contemplar as práticas curriculares e situações do quotidiano escolar, nem sempre enveredam por este caminho. Muitas destas instituições, por vezes, mantêm seus profissionais da Pedagogia em funções burocratas, perdendo o foco das questões mais importantes e inerentes às suas funções pedagógicas-formadoras.

Neste enfoque, a formação continuada acaba perdendo o seu objetivo e, muitas vezes, desmotivando os docentes que, pela sua formação técnica inicial, valorizam mais a formação específica à formação pedagógica, posição esta verificada em entrevista semiestruturada realizada com professores que atuam na docência técnica e tecnológica do Instituto Federal de Educação no Brasil.

O conhecimento científico-pedagógico está ligado à gestão do docente em mudar as suas atitudes em algo que seja pedagogicamente eficaz e adaptável às variadas necessidades dos que estão aprendendo, não perdendo de vista que o ensino ocorre em muitos contextos, essencialmente na interação com os alunos. 
A vivência do docente enquanto profissional em sala de aula, tem que ser levada em consideração. A necessidade de flexibilização das ações do professor, não podem ser unicamente baseadas em manuais pedagógicos, contrariando a ideia de que os professores têm que ser necessariamente formados nas realidades pedagógicas, pura e tão somente. Ou seja, que a vivência do docente enquanto profissional em sala de aula, não tem que ser levada em consideração, não permitindo, pois, um equilíbrio entre as práticas reflexivas e as pedagógicas.

O que se deseja e o que se torna necessária é uma formação que reúna prática e teoria, facilitando o aprendizado dos alunos, inquilinos primordiais dos saberes. Na educação, a prática reflexiva, bem assim, os conhecimentos científicos têm que conviver em harmonia, desenvolvendo formações que consigam articular as duas vertentes (Perrenoud, 2002). Ainda segundo o autor, a formação de professores tem que ter ligação íntima com a formação de pessoas, de seu crescimento, de sua capacidade de aprender com a experiência, refletindo sobre o que fariam, o que fizeram e o que resultou de tudo.

O desenvolvimento de um professor vem, na maioria das vezes, de suas experiências anteriores, como aluno, e de sua formação, que logo se transforma quando se dão os primeiros contatos com a realidade docente.

Entretanto, o que se verifica é que a capacidade reflexiva de cada docente não pode ficar distanciada das práticas pedagógicas, bem assim, o vice e versa. Com enfoque próprio, Damião (2011) refere que o bom professor é aquele que tem domínio coerente das competências que podem ser adaptadas e atualizáveis em cada situação,

Com base num questionário construído para caracterizar o perfil dos professores que atuam nos cursos de Educação Profissional e Tecnológico em um Instituto Federal de Educação no Brasil, bem como conhecer as suas percepções sobre a formação profissional para a docência aplicado a cerca de 30 profissionais, foi possível verificar que $72,5 \%$ possui mestrado e/ou doutorado e que em nenhum destes cursos houve formação didático-pedagógica, embora esteja implícita esta formação da graduação.

Os indagados se procuraram alguma formação que os levasse a obter formação pedagógica nos últimos 4 anos, 55\% dos professores informaram que não procuraram qualquer tipo de aperfeiçoamento profissional relativo à área pedagógica e que, dos questionados, apenas $1(3,4 \%)$ reconheceu o grande impacto que esta formação teve na vida profissional como docente (cf. Quadro 1).

Quadro 1

Aprimoramento de Práticas Pedagógicas

\begin{tabular}{lcc}
\hline \multicolumn{1}{c}{ Respostas } & Frequência & Percentagem \\
\hline Não procuraram & 16 & 55,2 \\
Não respondeu & 1 & 3,4 \\
Grande impacto & 1 & 3,4 \\
Impacto moderado & 8 & 27,6 \\
Pouco impacto & 3 & 10,4 \\
$\quad$ Total & 29 & 100.00 \\
\hline
\end{tabular}

\section{Abordagem técnica e a prática reflexiva}

Quando se almeja uma mudança na formação de professores, leva a pensar nas consequências que as novas práticas podem ter no aprendizado. Além disso, as mudanças implicam um comprometimento para quem as idealizou e, muito mais, para quem as implementa, sob pena de ficarem no mundo das ideias.

A perspectiva de buscar a prática reflexiva leva, antes de tudo, à própria reflexão, sugerindo, desta maneira, algum tipo de investigação (Damião, 2011), o que nem sempre é fácil devido à tendência natural de os envolvidos procurem soluções anteriores, mesmo que não as de maior propriedade para o caso.

Para que o professor possa trabalhar com os alunos essas capacidades, a análise crítica de si mesmo e do próprio trabalho passa a ser determinante, ou seja, a prática reflexiva passa a ser a mola mestra para analisar e avaliar ações educativas postas em uso, o que os leva à construção de novas perspectivas e novas reflexões. A prática reflexiva transforma o profissional, favorecendo o desenvolvimento de uma postura bastante mais receptiva às mudanças e desafios.

Dos professores que responderam ao questionário sobre questões ligadas à formação continuada $76 \%$ concordam que a aprendizagem dos alunos é influenciada pela ausência de formação continuada do professor. No entanto, 69\% entendem que sua performance em sala de aula não é afetada ou é pouco afetada com o conceito de "professor reflexivo". A experiência profissional de cada professor, o cotidiano das escolas e das aulas, bem como as conversas informais com outros professores, contribuem, indubitavelmente, para o enriquecimento da prática pedagógica daqueles atores.

Os professores criam, ao longo da sua experiência de ensino, saberes próprios, conectados à ação, que só podem ser elaborados mediante a prática (Shön, 1992).

O conhecimento do currículo é indiscutivelmente importante para lidar com o cotidiano escolar, demonstrando o saber pedagógico e técnico, relativamente ao assunto específico a ensinar. A ele, deve ser associado o conhecimento do "aprender a ensinar a refletir", para si e para os outros, sabendo, desta forma, reagir aos imprevistos vivenciados na profissão professor.

A visão de que ao professor cabe o papel fundamental de ensinar, não se questiona. Todavia, a prática docente envolve o conhecimento através da experimentação e reflexão não podendo estas dimensões serem negligenciadas dentro da perspectiva reflexiva. (Alarcão, 1996).

\section{A formação e seus responsáveis}

Os grandes responsáveis pela formação dos professores, em sua maioria, são as Universidades que, através de seminários, estudos de caso e outras formas de estudos, podem orientar sobre a prática reflexiva. Entretanto, estes caminhos, sozinhos, deixariam incompletas e aquém as necessidades intrínsecas à preparação de docentes, uma vez que é importante que o desenvolvimento profissional possa integrar 
dimensões diversas, tais como a formação didática, a formação pedagógica e a formação tecnológica. Estes centros de ensino resistem a ideia de integrar em seus currículos os saberes práticos, delegando aos formadores essa obrigação, eliminando, desta forma, a necessidade de se questionar a respeito desses saberes (Perrenoud, 2002).

É claro que incluir material didático na formação de professores no âmbito da prática reflexiva não é fácil, pois não há regras de procedimentos uniformes, nem as poderia haver: cada caso é um caso; cada vivência é única; cada experiência é uma experiência. De modo contrário, se assim não fosse, correr-se-ia o risco de tratá-las com produtos já elaborados e terminados, passando para soluções prontas, perdendo-se a possibilidade do aprofundamento dos saberes eventualmente pertinentes a cada situação.

Uma das questões propostas aos professores que participaram da pesquisa foi conhecer o seu grau de concordância, sobre se: "Existem vários programas de formação continuada ofertados pelo Instituto.". Foi possível constatar que $65,5 \%$ dos professores discordaram, enquanto apenas $17 \%$ assinalaram sua concordância.

Em entrevista realizada posteriormente, para verificar o que realmente estava sendo desenvolvido em relação à formação e à capacitação do professor, os entrevistados informaram que tinham frequentado um "pequeno" curso de iniciação enquanto docentes do Instituto. Porém, apesar de obrigatório, não eram cobrados tanto quanto à frequência ou quanto à conclusão.

A preocupação com a formação dos docentes existe, mas ainda é negligenciada ou relegada a planos secundários tanto por parte da Instituição como por parte dos próprios interessados no processo educativo.

Coerentemente com os dados obtidos com a questão anterior, quando instados a revelar sua concordância com a adequação dos cursos de formação continuada, $58,6 \%$ revelou que tais cursos não atendiam as suas necessidades, no entanto, 20,7\% dos professores sentiram-se atendidos neste quesito.

Isto nos leva a refletir sobre o porquê de os cursos deste tipo de formação não atenderem, de forma convincente e insofismável, a procura dos docentes da área técnica e tecnológica.

O distanciamento entre a formação pedagógica para os cursos onde são regularmente oferecidos e aos direcionados para os cursos técnicos e tecnológicos, em sua concepção, podem vir a ser os responsáveis pelos resultados do grau de interesse dos docentes deste segmento.

O grande problema, não está na pouca preocupação das universidades com o preparo pedagógico, fundamental na formação de professores, mas sim na diferença entre dois modelos distintos: o que se preocupa com a formação do professor propriamente dita e a formação que se completa com o preparo pedagógico-didático (Saviani, 2009).

O que na verdade se pode perceber é que raciocínio dos professores que lidam com questões matemáticas, que aprendem em sua graduação a pensar logicamente com teoremas e axiomas resistem, a princípio, a colocações não lógicas, hipotéticas e que fujam à realidade não abstrata, palpável. Lidar com colocações que não sejam absolutamente factíveis, fugindo das concepções binárias e dando cursos com formatação igual aos professores que atuam na área das ciências humanas é altamente desestimulante para os que atuam na área técnica e tecnológica. A linguagem precisa se coadunar com o mundo laboral em que, durante toda vida profissional, aprenderam a pensar e desencadear seu raciocínio. Talvez esta dissociação seja a causa de $50 \%$ dos questionados terem informado sua discordância à afirmação de que "Fiz inúmeros cursos de aprimoramento da formação pedagógica" constante do questionário por eles respondido.

\section{Ser professor}

A profissão de professor ainda permanece sendo a mesma de muitos anos e igual ao passado (Tardif e Lessard, 2008). Apesar da relevância dos saberes técnicos, é essencial compreender as dimensões das relações sociais, assim como suas práticas traduzidas em conhecimento pedagógico. E é esse aspecto que confere especificidade à função de educador, que se estende a um compromisso moral e a um comprometimento com os alunos (Abreu, 2009).

Ser professor é muito além da tarefa de ensinar ou transmitir conhecimentos. Não basta, para o exercício da docência, apenas a formação acadêmica, passando conhecimento adquiridos ou conteúdos teóricos (Flores, 2004; Machado, 2008; Damião, 2011). O entendimento do que é ser professor, passa pela superação da improvisação e falta de formação pedagógica, não menosprezando, contudo, a prática escola. O menosprezo pelo desempenho científico pode levar, como consequência evidente, a sobrevalorização da vivência do cotidiano do docente, depreciando o saber teórico e enaltecendo o saber prático. É assim necessária uma formação que reúna prática e teoria, facilitando, sobremaneira, o aprendizado dos alunos (Alarcão, 1996, 2003; Roldão, 1998).

Todavia, não se pode imputar à má, a pequena ou quase nenhuma formação didático-pedagógica dos professores, todos os problemas que a educação profissional enfrenta. Existem vários motivos que podem explicar a baixa motivação existente na profissão docente, como a questão de política de cargos e salários, pouco conhecimento das concepções do que é ser educador são alguns dos fatores que desestimulam aqueles que pretendem pensar na profissão como ponto estratégico de sua vida particular, afetiva e integrada na comunidade onde vivem.

$\mathrm{Na}$ pesquisa em questão, apuramos que $62 \%$ dos professores não estão satisfeitos com os salários percebidos muito embora $86,2 \%$ voltariam a escolher ser professor se tivessem que decidir de novo. E mais, 93\% declarou serem professores por opção pessoal. Ou seja, estão na profissão de educadores por vocação, 
fato este que não pode ser relegado a segundo plano e que precisa ser levado em consideração no que tange à dimensão pessoal dos professores e seu crescimento.

Para o desenvolvimento profissional dos docentes a melhoria nas condições de trabalho, a maior autonomia e capacidade de ação coletiva e individual estão intrinsecamente relacionadas (Avalos, 2011; Garcia, 1999).

A motivação para ingressar no mundo do ensino, reforça a importância da pessoa e do contexto no processo de tornar-se professor (Flores, 2001).

E dentro desta perspectiva, a pesquisa também revelou outro aspecto interessante a respeito de ser professor. Ainda em relação à dimensão à capacidade de ação coletiva, 96,5\% dos participantes do estudo destacaram que a conversa informal com seus colegas sobre como melhorar seu ensino, impactaram sim seu desenvolvimento enquanto professores, destacando-se o mesmo percentual para a importância da leitura de periódicos, teses e documentos relacionados ao seu desenvolvimento como professor.

Coerentemente com as respostas anteriores, os participantes confirmaram que perceberam seu crescimento profissional ao longo do tempo, apresentando um percentual de 93,1\%.

É preciso compreender que o desenvolvimento profissional e formação contínua fazem parte da mesma realidade que é a formação permanente dos professores (Formosinho, 2009) e que para ser professor, além das dimensões pessoal e relacional, existe, e tem que existir, a dimensão da formação profissional continuada e a agregação da teoria à prática, facilitando a aprendizagem dos alunos.

O que se espera é que a formação continuada possa contribuir para a atualização de métodos, disciplinas e conceitos, e para o desenvolvimento do professor como profissional, entendido, por autores como Nóvoa (1997), Day (1999), Hargreaves (1992) como processo, que pode ser individual ou mesmo coletivo, mas que deve estar inserido no contexto da escola.

\section{Considerações finais}

A complexidade do assunto ora abordado, suas nuances, resistências e aspectos ainda não totalmente desvendados por estudos científicos validados, nos deixa plenamente cientes da necessidade de se investigar mais aprofundadamente sobre o assunto, por outro lado, nos deixa sinal positivo de que o caminho deve ser perseguido.

A exposição aos poderes institucionais constituídos e as políticas públicas educacionais, sempre muito voláteis, constituem, muitas vezes empecilho ao desenvolvimento e aplicação de métodos menos conhecidos ou menos investigados.

A abordagem reflexiva tem demonstrado, pelos estudos até aqui desenvolvidos, que veio para complementar os saberes pedagógicos na formação inicial ou continuada de professores e deles não pode se desvincular ou distanciar. Essa confrontação entre o pedagógico e a prática nos faz remeter a processos da formação profissional, em sua formatação e aplicação, reorientando essas lógicas, nem sempre eficazes, para um direcionamento em que, numa negociação ganhaganha, os resultados benéficos sejam sentidos por todos envolvidos.

O que se percebe é que não há um único direcionamento que possa levar os professores a desempenharem suas funções docentes com profissionalismo, com satisfação, com propriedade e autoconfiança. A aplicação dos conhecimentos pedagógicos alinhados à prática de reflexão têm demonstrado, mesmo que ainda não esgotados seus estudos, que a aprendizagem se torna muito mais calma, mais receptiva e porque não, reflexiva.

O que se pretende clarear é que não há uma única direção no sentido do conhecimento, seja ele de saberes pedagógicos, específicos ou de experiência, vivência, quando se pretende dar contributo maior para a formação de professores.

A importância de ações que integrem em seus propósitos as necessidades do aprendizado, precisam ser implementadas com firmeza não deixando, por um lado, a cautela necessária ao não conhecimento total de suas consequências que poderiam, de maneira inversa, causar mais constrangimentos e problemas que soluções.

Tais cuidados, por outro lado, não podem ser obstáculos cabais para que o aprendizado seja banido dos corredores escolares, dos processos reflexivos, dos professores como pessoas que pensam em ser professores em sua plenitude.

\section{Referências.}

Abreu, G. R. (2009). Ressignificação da formação de professor de ensino técnico profissional: Por uma prática reflexiva na reconstrução de sua identidade. Revista Profissão docente on line. Uberaba, (9) 21,114-132. Disponível emhttp://www.revistas.uniube.br/index.php/rpd

Alarcão, I. (1996). Formação reflexiva de professores. Porto. PT: Porto Editora.

Alarcão, I. (2003). Professores reflexivos em uma escola reflexiva. São Paulo: Cortez.

Amado, J. (2013). Manual de investigação qualitativa em Educação. Imprensa da Universidade de Coimbra: Gráfica de Coimbra, PT.

Avalos, B. (2011). Teacher professional development in Teaching and Teacher Education over ten years. In Teaching and Teacher Education (pp. 10-20). Elsevier Ltd: UK.

Damião, M. H. (2011). Algumas considerações de ordem crítica à perspectiva da prática reflexiva. Revista Portuguesa de Pedagogia Extrasérie, 441-452.

Day, C. (2007). A liderança e o impacto do Desenvolvimento Profissional Contínuo dos Professores. In J. C. Morgado \& M. I. Reis (Orgs.) Formação e desenvolvimento profissional docente: Perspectivas Europeia (pp. 30-39). Universidade do Minho: CIED. 
Formosinho, J.O. (2009). Desenvolvimento profissional dos professores. In J. Formosinho. Formação de Professores. Aprendizagem e Acção docente (pp. 221-284). Porto: Porto Editora.

Flores. M. A. (2001) Formação docente e identidade profissional: tensões e (des)continuidades. Educação. Porto Alegre, v. 38, n. 1, p. 138-146, jan.-abr. 2015. Disponível em

http://revistaseletronicas.pucrs.br/ojs/index.php/faced /article/view/15973/12761> Acesso em 18 de junho de 2015

Flores, M. A. (2004). Dilemas e desafios na formação de professores. In: M. Moraes, J. Pacheco, M. Evangelista (Orgs.). Formação de professores: perspectivas educacionais e curriculares (pp. 127160). Porto: Porto Editora.

García, C. M. (1999). Formação de professores: para uma mudança educativa. Porto: Porto editora

Hargreaves, A. (1992). Cultures of teaching: A focus for change. In A. Hargreaves \& M. G. Fullan (Eds.), Understanding teacher development (pp. 216-240). New York: Teachers College Press.

Machado, L. S. (2008). Diferenciais inovadores na formação de professores para a educação profissional. Revista Brasileira da Educação Profissional e Tecnológica, (1)1, 9-22.
Nóvoa, A. (Org.) (1992) Vidas de professores. Porto: Porto Editora.

Nóvoa, A. (1997). Os professores e a sua formação (3 ed.). Lisboa: Dom Quixote.

Nóvoa, A. (1999). A formação de professores e a profissão docente. In A. Nóvoa (Org.), Os professores e sua formação (pp. 9-33). Lisboa: Dom Quixote.

Perrenoud, P. (2002). A prática reflexiva no oficio de professor - Profissionalização e razão pedagógica. Porto Alegre: Armed.

Roldão, M. C. (1998). Que é ser professor hoje? - A profissionalidade docente revisitada. Revista da ESES Nova Série, 9.

Saviani, D. (2009). Formação de professores: aspectos históricos e teóricos do problema no contexto brasileiro. Revista Brasileira de Educação, 14(40), 143-145.

Schön, D. A. (1992). Educating the eflective practitioner. San Francisco: Jossey Bass.

Tardif, M., \& Lessard, C. (2008). O oficio do professor: História, perspectivas e desafios internacionais. Petrópolis: Ed. Vozes. 